Current psychology letters

\title{
The role of eye height in judgment of an affordance of passage under a barrier
}

Romaric Marcilly and Marion Luyat

\section{(2) OpenEdition}

Electronic version

URL: http://journals.openedition.org/cpl/3443

DOI: $10.4000 / \mathrm{cpl} .3443$

ISSN: $1379-6100$

Publisher

Centre PsyCLÉ

\section{Electronic reference}

Romaric Marcilly and Marion Luyat, "The role of eye height in judgment of an affordance of passage under a barrier », Current psychology letters [Online], Vol. 24, Issue 1, 2008 | 2008, Online since 15 March 2008, connection on 08 September 2020. URL : http://journals.openedition.org/cpl/3443 ; DOI : https://doi.org/10.4000/cpl.3443 


\section{THE ROLE OF EYE HEIGHT IN JUDGMENT OF AN AFFORDANCE OF PASSAGE UNDER A BARRIER}

\section{Romaric Marcilly}

Laboratory of Industrial and Human

Automatic, Mechanic and Informatics,

CNRS UMR 8530

University of Valenciennes and of Hainaut-Cambrésis, le Mont Houy-59313

Valenciennes Cedex 9

E-mail: romaric.marcilly@univ-

valenciennes.fr

\section{Marion Luyat}

Laboratory of Functional Neurosciences and Pathology, CNRS UMR 8160 and University of Lille - CHRU 59037 Lille 


\section{Résumé}

D’après la théorie écologique de la perception (Gibson, 1979), l'observateur-acteur, au cœur de ses multiples interactions avec l'environnement, perçoit des affordances, c'est-à-dire des opportunités d'action. Cette perception serait directe et nécessiterait la prise d'information qui spécifierait la relation entre les caractéristiques de l'environnement et les propriétés de l'individu. L'objectif de cette recherche est d'étudier le rôle de la hauteur des yeux dans des jugements perceptifs de passage sous une barre. Huit participants ont effectué des jugements verbaux à propos de la hauteur minimale d'une barre sous laquelle ils pouvaient passer sans baisser la tête en marchant à vitesse normale. La hauteur des yeux perçue était également mesurée. Les jugements étaient effectués dans trois conditions de vision: (i) utilisation de lunettes à verres neutres (condition de base), (ii) utilisation de lunettes avec verre prismatique (déviation vers le bas de $20 \mathrm{dp}$ ) et (iii) après adaptation à ces lunettes. Les résultats montrent que les deux types de jugements (hauteur minimale et hauteur des yeux perçue) sont affectés par le port des prismes. Ils révèlent notamment un effet de I'adaptation aux prismes (after-effect) significatif. Cet after-effect est mis en évidence pour les deux types de jugements. Ces résultats étayent l'hypothèse selon laquelle la hauteur des yeux effective, souple et adaptable, est calibrée par rapport à la scène visuelle. En retour, la hauteur des yeux effective peut servir à estimer des potentialités d'action pour l'organisme.

\section{Abstract}

According to the ecological theory of visual perception (Gibson, 1979), the perceiver-actor perceives affordances (i.e. opportunities of action) through multiple interactions with the environment. This perception is direct and consists in picking up information that specifies the relationship between the environment's characteristics and the perceiver-actor's properties. The aim of the work reported here was to study the role of eye height in the perceptual judgments of passability under a barrier. Eight participants were asked to verbally judge the minimal height of a barrier under which they could pass without lowering their head. Their perceived eye height was also measured. The judgments were made in three viewing conditions: (i) wearing neutral glasses (the baseline condition), (ii) immediately after putting on glasses with prismatic deviation (a 20PD downward deviation) and (iii) after adaptation to the prismatic deviation. The results showed that the two judgments (minimal barrier height and perceived eye height) were affected in the same way by the prisms. Most significantly, an after-effect occurred and had a similar impact on the two judgments. These results suggest that the effective eye height is not fixed but can be adapted and calibrated relative to the visual array. Accordingly, effective eye height can help estimate action potentialities for the organism.

Key-words: affordance; eye-height ratio; perception; prismatic deviation; passability

\section{ACKNOWLEDGMENTS}

This research was carried out under the auspices of the GDRE's "HumAn-Machine Systems in Transportation - HAMASYT" program 


\section{INTRODUCTION}

Through our various interactions with our environment, we generally guide our actions in an appropriate manner and achieve our goals without injuring ourselves. During locomotion, for example, we select the ground areas that support our weight and avoid inappropriate surfaces and obstacles that could potentially prevent or hinder movement. Likewise, we adjust our walking speed to suit the nature of the terrain, by slowing down when the ground is rough and accelerating when conditions are more favorable. The affordance neologism (introduced by James Jerome Gibson in 1979) illustrates very well this ability to guide our behavior by perceiving what the environment offers us in terms of action opportunities. Affordance can be defined as the functional utility of an object, a surface or an event for an animal with given physical characteristics (height, weight, etc.) and a number of action capabilities which depend on the species, the animal's ontogenetic development and/or more idiosyncratic characteristics (Regia Corte, Luyat, Miossec \& Darcheville, 2004). In the literature, recent debate has centered on the ontology of affordance (for a review, see Luyat \& Regia-Corte, in press). Researchers argue over whether the affordance is an inherent property of the environment (Turvey, 1992) or an emergent property of the animalenvironment system (Stoffregen, 2003). However, in both of these theoretical views, the notion of affordance relies on the fact that the environmental properties (height, width, weight, distance, etc.) are not evaluated on an extrinsic scale with the units of measurement used in physics. In fact, the dimensions are measured on an intrinsic scale according to certain relevant properties of the perceiver-actor, such as its own height, width and running speed (Oudejans, Michaels, Bakker \& Dolné, 1996).

For example, in Warren's pioneering study (1984), tall and short participants were asked to view a set of stairs with different riser heights and then, without performing the real action, had to judge whether they could climb the various stairs with a normal bipedal stance. The results revealed that whatever the participant's height, perceptual judgments of the critical riser height could be expressed as a constant proportion of the participant's leg length (observed $\pi_{\mathrm{c}} \approx 0.88$ ) This fitted well with the individual's actual stair-climbing capabilities computed from an a priori biomechanical model of climbability, where $\pi_{c}=0.88$. This critical pi number $\left(\pi_{c}=E / A\right)$ is an invariant ratio obtained by dividing the characteristics of the environment ( $E$ : critical riser height) by the relevant property of the individual ( $A$ : leg length). In the context of direct perception, perceiving the affordance of climbing would mean detecting this $\pi$-number (i.e. the information specifying that we are able to climb a stair) in the stimulation pattern. The ratio relative to the eye height of the perceiver-actor is a potential candidate for specifying such an affordance.

The concept of eye height can be used in several ways. Real eye height refers to the actual height of an observer's gaze off the level floor (anthropometrical standing eye height). Effective eye height (see Wraga, 1999) refers to the projection of the observer's eye height into the environment. The effective eye height can be used to measure the dimensions of an object, as long as the perceiver-actor and the perceived object are on the same plane. Moreover, the perceived eye height is the estimate of the effective eye height by a perceiver-actor. In an open visual field, effective eye height is redundant to the explicit visual horizon, which is the apparent intersection of the earth and sky. However, under 
many circumstances (e.g. an indoor environment), the explicit horizon is not directly available. In such cases, the effective eye height relies on an approximation of the horizon: the implicit horizon. The latter is conveyed by information such as the ground texture convergence and the convergence lines at the vanishing point located at the implicit horizon. The implicit horizon is deduced perceptually rather than seen explicitly. However, effective eye height is also available through a combination of three vestibular/ocular-motor cues: the vertical orientation of the head with respect to gravity, the position of the eye relative to the head, and the location of a point of fixation on the retina (Matin \& Li, 1992).

Since the line of sight is orthogonal to the object's vertical orientation (see Figure 1), the geometrical rules of optics enable expression of the object's dimensions (such as its height and width) as an eye-height ratio (Sedgwick, 1980). Moreover, the anthropometric relationship between eye height and other body dimensions (such as body height and width) is usually constant. Thus, perceiving an object's dimensions as an eye-height ratio provides the perceiver-actor with information on the relationship between the characteristics of the environment and his/her own dimensions. Since an affordance corresponds to this type of relation, perception of affordance means that information such as the eye-height ratio has to be picked up.

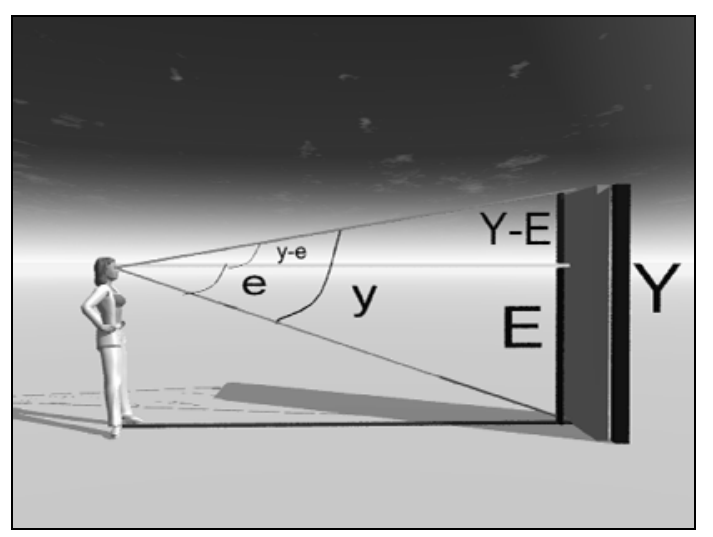

Figure 1. Illustration of the geometrical rules of optics that express the height of the object as a proportion of the perceiver-actor's eye height (i.e. an eye-height ratio), where $Y$ is the object's total height, $E$ is the portion of the object below the horizon, and $y$ and $e$ are the respective heights expressed as visual angles. The height of the object depends on the eye height and is expressed as a visual angle: $Y / E=1+\tan (y-e) / \tan (e)$.

Several experimental studies have demonstrated that the perceived limits of an affordance are based on the eye-height ratio. When examining the affordance of passage through an aperture, Warren \& Whang (1987) measured the critical aperture (as a width) that enabled passage without having to turn the shoulders sideways. In Experiment 3, they reduced the effective eye height (EEH) by introducing a raised false-floor in the room where the aperture to be estimated was located. Their results showed that judgments of the critical aperture $\left(A_{\text {minp }}\right)$ were lower in the raised floor condition while the aperture/eye-height ratio (i.e. $\left.A_{\text {minp }} / E E H\right)$ remained constant. Indeed, this ratio was 0.29 in the raised floor condition and 0.28 in the flat floor condition. Moreover, participants were asked to verbally evaluate different absolute distances between themselves and the aperture. It was found that the raised floor did not have a significant effect on the verbal distance estimations. Thus, critical 
passability through an aperture appears to be judged on the basis of an eye-height ratio. Using another method, Mark (1987) studied the involvement of eye height in the perception of maximum riser height $\left(\mathrm{R}_{\max }\right)$ and maximum sitting height $\left(\mathrm{SH}_{\max }\right)$. The real and effective eye heights were increased by strapping blocks (each $10 \mathrm{~cm}$ in height) to the perceiveractors' feet. Lower leg and total leg lengths were thus increased, whilst leaving the upper leg length unchanged. From a biomechanical point of view, $R_{\max }$ was equal to the total leg length (L) plus the upper leg length $\left(L_{1}\right)$ minus the lower leg length $\left(L_{2}\right): R_{\max }=L+L_{1}-L_{2}$ where $L=L_{1}+L_{2}$ and $R_{\max }=2 L_{1}$. The real $R_{\max }$ was not affected by the blocks because it depends on the upper leg segment (see Figure 2). In contrast, the blocks increased the real $\mathrm{SH}_{\max }$ because it depends on $L_{1}$ and $L_{2}$. In other words, adding blocks to one's feet is not comparable to actually being taller because the body's normal proportions are not maintained - only the lower part of the leg is increased. As a result, adding a "platform sole" does not allow the wearer to climb higher stairs but it does enable him/her to sit on higher chairs. Thus, if individuals use the same eye-height ratio, with and without blocks, to judge $\mathrm{R}_{\max }$ and $\mathrm{SH}_{\max }$, they should overestimate their real $\mathrm{R}_{\max }$ and underestimate their real $\mathrm{SH}_{\max }$ when wearing blocks.

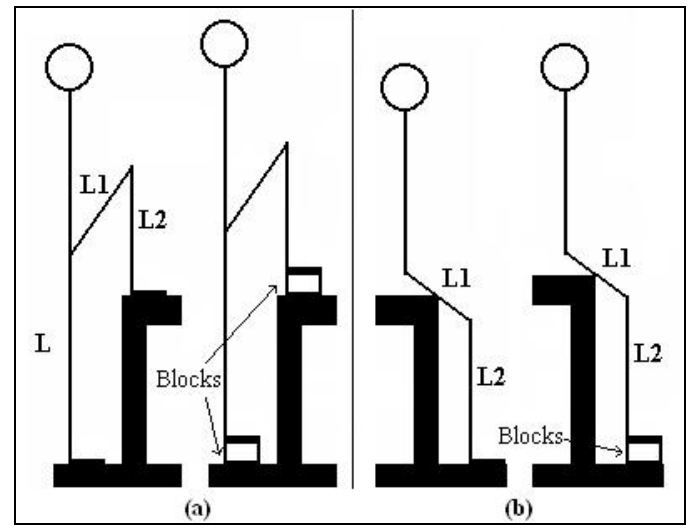

Figure 2. Schematic representation of biomechanical models for $\mathrm{R}_{\max }$ (a) and $\mathrm{SH}_{\max }$ (b).

Mark's results showed that there was no significant difference between the eye-height ratio values that the participants (who were not allowed to practice with the blocks beforehand) used to judge $\mathrm{R}_{\max }$ with and without blocks. The same was true for $\mathrm{SH}_{\max }$ judgments. Indeed, the eye-height ratios for the perceived $\mathrm{R}_{\max }$ and $\mathrm{SH}_{\max }$ in the first trial were respectively 0.445 and 0.466 with blocks and 0.457 and 0.454 without blocks. However, the eye-height ratios for the real $\mathrm{R}_{\max }$ and $\mathrm{SH}_{\max }$ with blocks were 0.437 and 0.492 . This means that the same eye-height ratio was used with and without blocks and thus caused the real $\mathrm{R}_{\max }$ and $\mathrm{SH}_{\max }$ to be overestimated and underestimated, respectively. The individuals were judging opportunities for action as if their biomechanical properties had not changed. Between each set of judgments, individuals were allowed to move around on the blocks. At the last set of judgments (in Experiment 2), the participants' judgments were based on new eyeheight ratios, i.e. ratios that had been recalibrated with respect to the true possibilities for action. The eye-height ratios for $\mathrm{R}_{\max }$ and $\mathrm{SH}_{\max }$ for the last trials with blocks were 0.429 and 0.482 , respectively very close to the real $\mathrm{R}_{\max }$ and $\mathrm{SH}_{\max }$ eye-height ratios with blocks (0.437 and 0.492$)$. Thus, in order to detect an affordance, the perceiver-actor probably uses an eye-height ratio that has been previously learned. 


\section{GOAL OF THE PRESENT EXPERIMENT}

Here, by directly manipulating the effective eye height with prisms, we aimed to show that the opportunity to pass under a barrier could be perceived according to a particular eyeheight ratio. Moreover, we sought to establish whether or not the effective eye height (subserved by a plastic mechanism) can be learned. Van der Meer (1997) defined the critical point of this affordance as the minimum height of a horizontal barrier under which an individual could pass without lowering the head. The limit of this affordance can be described as a $\pi$ ratio: $\pi=\mathrm{BH}_{\min } / \mathrm{H}$, where $\mathrm{BH}_{\min }$ is the minimum height of the barrier and $\mathrm{H}$ is the standing height of the perceiver-actor. Theoretically, an individual can pass under a barrier if this ratio is greater than 1. If it is not, he/she must either (i) adapt his behavior (by ducking the head downwards and forwards, for example) in order to pass safely or (ii) stop the action. In order to quantify this real critical point, Van der Meer filmed her participants walking freely under a barrier that was positioned at different heights. The height at which they began to duck was defined as the critical point of the affordance. The results showed that adults walking at a normal speed began to lean their heads when the barrier height was 1.038 times their own height. Thus, when performing the real action, the effective ratio of the affordance's critical point is $\pi=\mathrm{BH}_{\min } / \mathrm{H}=1.038$.

Since real eye height $(E H)$ is a constant (c) of body height $(E H=c \times H)$, we suggest that the effective $\pi$ ratio can be also formulated according to the participant's real eye height and $c$.

With $\mathrm{H}=\mathrm{EH} / \mathrm{c}, \pi=\mathrm{BH}_{\min } / \mathrm{H}$ is equivalent to $\pi=\mathrm{BH}_{\min } /(\mathrm{EH} / \mathrm{c})=\mathrm{BH}_{\min } \times(\mathrm{c} / \mathrm{EH})$.

Thus, $\pi=\left(\mathrm{BH}_{\min } / \mathrm{EH}\right) \times \mathrm{c}=1.038$. Let $\pi^{\prime}$ be the eye-height ratio of the affordance's critical point $\left(\pi^{\prime}=\mathrm{BH}_{\min } / \mathrm{EH}\right)$. Thus, $\pi=\pi^{\prime} \times \mathrm{C}=1.038$. This eye-height ratio $\left(\pi^{\prime}\right)$ can be obtained by dividing 1.038 by c, i.e. $\pi^{\prime}=1.038 / \mathrm{c}$.

According to the ecological approach to perception, perceiver-actors should detect this ratio $\left(\pi^{\prime}\right)$ when they have to judge visually whether or not they can pass under a barrier. In order to test this hypothesis, we modified the effective eye height using prismatic glasses.

The method was composed of four successive sessions with three different experimental conditions. First, the perceiver-actors judged their eye height and their critical height of passability without any optical deviations (the baseline condition). Second, the same judgments were made wearing prismatic glasses (the prism condition). Following an adaptation period (during which the perceiver-actors had to perform a target-based motor activity while wearing the prisms), a third session was performed after removal of the prismatic glasses (the after-effect condition).

The prisms deflect the light reflected by the surfaces and the objects by a set number of degrees, translating the visually perceived position of surfaces and objects into a new "virtual" position. For example, in the case of 20PD base-up prisms, the light is deflected downward by $11.5^{\circ}$. The perceiver-actor sees the entire scene lower than it really is. If the perceiver-actor is prevented from adapting to the deviation and must adjust a target to his eye height, he/she will thus place it higher than it really is, in order to compensate for the downward deflection of the light. During the adaptation phase, he has to look constantly in 
the direction of the deflection and the resting position of the eyes is recalibrated (Howard, 1982). Thus, the effective eye height could be changed by the prismatic paradigm. In particular, after the adaptation to base-up prisms, a downward shift in perceived eye-height judgments has been observed, when compared with initial judgments (Ooi, Wu \& He, 2001).

In the present experiment, we applied 20PD base-up prisms. If perception of $\mathrm{BH}_{\min }$ is specified by an eye-height ratio, it should be shifted in the same manner as perceived eye height. Thus, compared with the baseline condition, the eye height and $\mathrm{BH}_{\text {min }}$ judgments should be higher in the prism condition. Moreover, a significant after-effect (i.e. lower judgments in the after-effect condition than at baseline) would argue in favor of eye height recalibration. Eye height adaptation (recalibration via motor activity performed during the adaptation phase) would suggest the existence of a plastic learning mechanism that calibrates body information against the visual layout.

\section{METHOD}

\section{PARTICIPANTS}

Eight volunteers (5 women and 3 men with a mean (SD) age of 22.37 (1.37), all undergraduate psychology students) gave their informed, written consent to participation in the experiment. All had vision that was normal or corrected to normal by lenses.

\section{MATERIAL AND APPARATUS}

The experiment took place in a test room where a small corridor $(2.50 \mathrm{~m} \mathrm{high,} 97 \mathrm{~cm}$ wide and $3 \mathrm{~m}$ long) was demarcated by black, opaque curtains. The floor was covered with small phosphorescent spots (about $3 \mathrm{~cm}$ in diameter). On the wall opposite to the participants, an adjustable, horizontal board $(30 \times 40 \times 2 \mathrm{~cm})$ was fixed to a long, vertical bar (see Figure 3) and was used as a cursor. The experimenter could adjust the height of the board from a minimum of $24 \mathrm{~cm}$ from the ground to a maximum of $224 \mathrm{~cm}$. Graduations on the bar enabled the board's height from the ground to be read. The edge of the board facing the participants was colored with phosphorescent paint. When the lights were turned off, only the board's edge $(2 \mathrm{~cm} \times 40 \mathrm{~cm})$ and the phosphorescent spots scattered on the ground were visible. All sessions other than the prism adaptation phase were performed in the dark with the phosphorescent spots on the ground visible. Even though this method created an impoverished environment, it appeared to be preferable to limit visual cues and thus prevent the participants from using the latter as the basis for their judgments. Participants stood upright $280 \mathrm{~cm}$ from the wall with the adjustable, luminous board edge and in such a way that the board's horizontal centre coincided with their sagittal plane. 


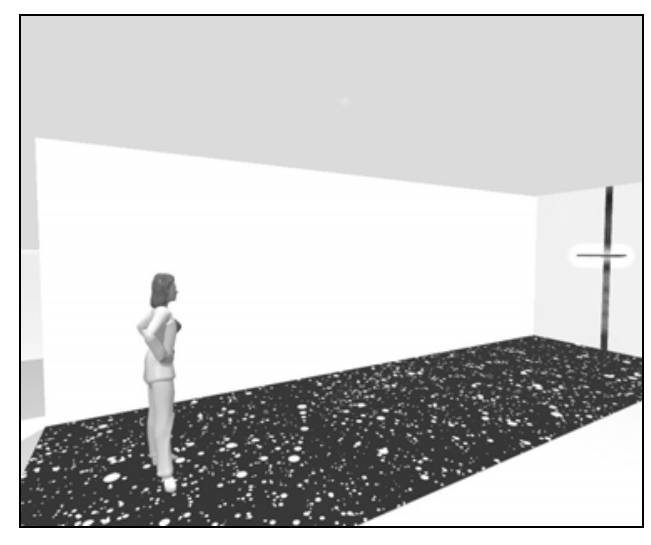

Figure 3. Schematic representation of the experimental apparatus.

\section{Procedure}

The participants were tested individually in the dark and had to indicate to the experimenter the positions at which the board's luminous edge corresponded to two height estimates: (i) their perceived minimal barrier height $\left(\mathrm{BH}_{\min }\right)$ and (ii) their perceived eye height $\left(\mathrm{EH}_{\mathrm{p}}\right)$. $\mathrm{BH}_{\min }$ was defined as the minimum perceived height of a horizontal barrier under which the participant could pass without lowering his (her) head. We told the participants that the barrier was represented by the thin, luminous, rectangular edge of the board. The $\mathrm{BH}_{\text {minp }}$ was judged without performing the real action. The perceived eye height was defined as the height at which the individual perceived that his (her) horizontal line of gaze intersected the facing wall ahead, with the luminous rectangular edge representing that height.

The $\mathrm{BH}_{\text {minp }}$ and $\mathrm{EH}_{\mathrm{p}}$ judgments were each estimated six times in three different visual conditions. In condition 1 (baseline), the participant wore glasses with no correction in the dark. After his (her) last judgment in this condition, he (she) closed his (her) eyes while the experimenter replaced the normal glasses with 20PD base-up prismatic ones. The participant opened his (her) eyes and made the same judgments with prisms (condition 2: prism condition). At the end of the last judgment in this condition, an adaptation phase began. The room lights were turned on and the participant was asked to stand $2 \mathrm{~m}$ away from another wall. He (she) was given $20 \mathrm{~min}$ to practice hitting two targets drawn on the wall (respectively 130 and $170 \mathrm{~cm}$ from the ground) with small, smooth balls. Next, he (she) was placed in the same posture as in the first two conditions and the lights were again switched off. The participant closed his (her) eyes while the experimenter replaced the prismatic glasses with the normal ones. Then, once he (she) had opened his (her) eyes, the participant was told to make the same judgments as before (condition 3: after-effect condition). Once this session was over, the real standing height (i.e. minimum barrier height) and eye height were measured and the participant was debriefed.

During the six trials, the initial position of the board was set at either $111 \mathrm{~cm}$ or $224 \mathrm{~cm}$ from the ground. The order of presentation of this initial position was counterbalanced over the six trials. Under verbal instructions from the participant, the experimenter (who was behind a black curtain and not visible during the test) raised or lowered the board until the desired position was reached. Each participant performed 6 judgments in 3 viewing conditions for the 2 requested heights (tasks), i.e. a total of 36 trials.

\section{REsUlts}

The mean height judgment in centimeters was calculated over the six trials for each viewing condition and for each task. The results are shown in Figure 4. 


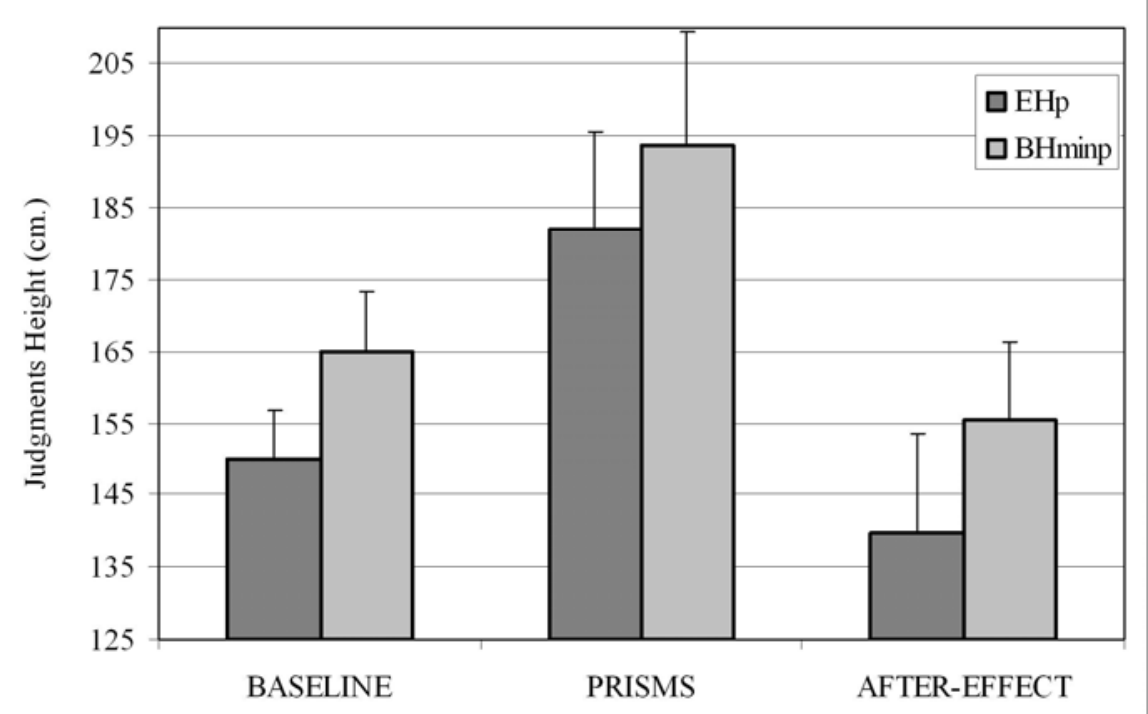

Figure 4. Mean height (in $\mathrm{cm}$ ) estimated by the participants according to the type of judgment and the viewing condition. Bars represent the SD.

The assumptions required for an analysis of variance (a normal distribution and sphericity of the variance-covariance matrix) were met at $p>$.1. A two-factor ANOVA (3 viewing conditions $\times 2$ tasks) with repeated measures on both factors was carried out on the mean height judgments (in $\mathrm{cm}$ ). The analysis showed a significant effect of both viewing condition $\left[F_{(2,14)}=61.55 ; p<.0001\right]$ and task $\left[F_{(2,15)}=55.79 ; p<.0001\right]$. The interaction between the two factors was not significant $\left[F_{(2,14)}=.58\right.$; $p=.57$ ]. Post-hoc comparisons (using the Newman-Keuls test) revealed that relative to the baseline condition $(M=150.10 \mathrm{~cm})$, the perceived eye height was greater in the prism condition $(M=181.90 \mathrm{~cm} ; p<.001)$ and lower in the after-effect condition (i.e. after the adaptation phase; $M=139.76 \mathrm{~cm} ; p<.05)$. The same pattern of results was observed for $\mathrm{BH}_{\text {minp }}$ judgments; compared with the baseline condition $(M=165.03 \mathrm{~cm}), \mathrm{BH}_{\min }$ judgments were greater in the prism condition $(M=193.83 \mathrm{~cm} ; p<.001)$ and lower in the after-effect condition $(M=155.53 \mathrm{~cm} ; p<.05)$.

Moreover, a correlation analysis (testing the significance of the Bravais-Pearson coefficient) showed that in each of the three viewing conditions, the two judgments $\left(\mathrm{BH}_{\min }\right.$ and $\left.\mathrm{EH}_{\mathrm{p}}\right)$ were strongly and significantly correlated: $r=.81, t(6)=3.40, p=.01$ for the baseline condition, $r=.72$, $t(6)=2.56, p<.05$ for the prism condition and $r=.90, t(6)=5.04, p<.01$ for the after-effect condition.

The participants' real eye height and standing height were, on average, $156.92 \mathrm{~cm}$ and $168.24 \mathrm{~cm}$, respectively. Thus, the eye height corresponded to $93 \%(S D=.007)$ of the standing height $(c=.93)$. We have suggested (see the Introduction) that since eye height $(E H)$ is a constant $(c)$ of the body height $(\mathrm{EH}=\mathrm{C} \times \mathrm{H})$, the effective $\pi$ ratio can be expressed according to the participant's real eye height: $\pi^{\prime}=\mathrm{BH}_{\min } / \mathrm{EH}=\mathrm{BH}_{\min } /(\mathrm{H} \times \mathrm{c})=\left(\mathrm{BH}_{\min } / \mathrm{H}\right) \times(1 / \mathrm{c})=1.038 / \mathrm{c}$. In the present experiment, the participants' average $\pi^{\prime}$ ratio was estimated to be 1.11 : $\pi^{\prime}=1.038 / .93=1.11 ; S D=.009$. The data collected in the baseline-condition enabled computation of the participants' natural $\pi_{p}^{\prime}$ ratio: $\pi_{p}^{\prime}=\mathrm{BH}_{\text {minp }} / \mathrm{EH}_{\mathrm{p}}$, where $M\left(\mathrm{BH}_{\text {minp }}\right)=165.03 \mathrm{~cm}$ and $M\left(\mathrm{EH}_{\mathrm{p}}\right)=150.10 \mathrm{~cm}$. This yielded an average value of $1.10(S D=.03)$. Comparing $\pi_{p}^{\prime}$ with $\pi^{\prime}$ in Student's $t$ test did not reveal any significant difference $(t(7)=-1.167 ; p=.28)$.

In order to establish the precision of the eye-height judgment for the baseline condition, we compared the judgments of eye height $(M=150.10 \mathrm{~cm} ; S D=6.79 \mathrm{~cm})$ with the measurements of the real eye height $(M=156.92 \mathrm{~cm} ; S D=3.51 \mathrm{~cm})$. A Student's $t$ test 
revealed a significant difference: $t(7)=2.86 ; p=.026$. For the baseline condition, the perceived eye height was judged to be lower than the real eye height, with an average underestimation of $4.33 \%$.

\section{DISCUSSION}

In the present work, we sought to establish a link between effective eye height and the critical limit of an affordance of passage under a barrier. Van der Meer (1997) has shown that at normal walking speed, the real minimal height under which adults passed without lowering their head was 1.038 times their standing height. Her experiment thus determined the real critical point of this affordance. The objective of the present experiment was to test whether the eye-height ratio could possibly provide relevant information on deciding what future action to take (i.e. to duck the head or not). We directly modified the effective eye height by using base-up prisms. The experimental method featured three different conditions: (i) a baseline condition (without prisms), (ii) a prism condition and (iii) an after-effect condition (without prisms but just after a prism adaptation phase). In each of these conditions, both perceived eye height and perceived minimal barrier height were measured.

The results showed that viewing conditions had a clear effect on the perceived heights. The perceived eye height and the perceived minimal barrier height were greater in the prism condition $\left(181.90 \mathrm{~cm}\right.$ and $193.83 \mathrm{~cm}$, respectively) than in the baseline condition $\left(\mathrm{EH}_{\mathrm{p}}=150.10 \mathrm{~cm}\right.$ and $\mathrm{BH}_{\min }=165.03 \mathrm{~cm}$ ). Moreover, after a prism adaptation phase (which consisted in throwing balls at two different targets on a wall), these two judgments were lower than in the baseline condition (139.76 cm and $155.53 \mathrm{~cm}$, respectively). The lack of significant interaction between the two factors (namely the viewing condition and the type of judgment) suggests that the deflection produced by the prisms (in the prism condition and the after-effect condition) has a similar-sized effect (or, at least, one that does not significantly differ) on the perceived eye height and minimal barrier height. The perceived eye-height ratios in the different viewing conditions were not significantly different: 1.10, 1.06 and 1.11 for the baseline, prism and after-effect conditions, respectively. Moreover, the strong positive correlations between the two judgments (observed in each of the three viewing conditions) confirmed that the perceived eye height and the perceived critical limit of the affordance are closely linked. These overall results agree with ecological studies of the role of eye height (e.g. Warren \& Whang, 1987; Mark, 1987). Indeed, we also showed that modification of the perceived eye height leads to an equivalent change in the perceived critical limit of the affordance. In order to decide whether or not they can pass under a barrier without lowering their head, individuals may pick up, in the energetic array, an eye-height ratio $\left(\pi^{\prime}{ }_{p}=1.10\right)$ which directly specifies the limits of their actions.

Moreover, since the perceived eye height was lower in the after-effect condition, the adaptation procedure (which involved aiming at two targets while wearing base-up prisms) seems to be enough to change the effective eye height. During the adaptation phase, the participants perceived the consequences of their actions as being lower than they really were. They could scale the perception of their action capacities on their new, decreased effective eye height: the action enabled recalibration of the perception of affordances. The fact that the post-adaptation perceived eye height was underestimated (relative to the baseline condition) could be interpreted, as suggested by Howard (1982), as a recalibration in the sense of the position of the eyes in the head (sustained by a change in the innervation in the agonistic and antagonistic muscles) and in the sense of the head position. Thus, our results suggest that affordance perception does not depend solely on optical invariants (the eye-height ratio specified in the optic array) but rather on a multimodal invariant given by the global array (the eye-height ratio specified by optical, vestibular and oculomotor components). 
The picking up of this information may be learned, subserved by a plastic mechanism, by the consequences of action (after-effect).

However, the classical approach offers an alternative view of the use of eye-height ratio; the perceived size of an object $\left(S_{p}\right)$ is sensed to be equal to its retinal image $\left(S_{\alpha}\right)$ multiplied by its perceived distance $\left(D_{p}\right)$ from the observer $\left(S_{p}=S_{\alpha} \times D_{p}\right)$. In the present experiment, the base-up prisms could also have affected the perceived distance. According to the classical approach, this would in turn shift the perceived object's height. In the prism condition, for example, underestimation of the perceived distance could have led to underestimation of the perceived heights (see the equation above). To compensate for this decrease in height perception, the observers must increase their final judgments of $\mathrm{BH}_{\text {min }}$. In addition, Ooi, $\mathrm{Wu} \& \mathrm{He}$ (2001) used base-up prisms to show that perceived distance (estimated in a blindfolded-walking paradigm) was affected by the prisms both during exposure and after the adaptation phase. In particular, these authors found that distance overestimation as an after-effect of prism adaptation was due to a lower perceived eye height. Thus, our results do not rule out an effect of prisms on the perceived distance. However, a geometrical description of the optical array allows one to independently express the perceived height and the perceived distance as eye-height ratios. The object's height is defined as an eye-height ratio by the following equation: $Y / E=1+\tan (y-e) / \tan (e)$, where $Y$ is the total height of the object, $E$ is the portion of the object from the ground to the horizon and $y$ and e express these heights as visual angles (Wraga \& Proffitt, 2000). The equation concerning the perceived distance is $Z / E=1 / \tan (e)$, where $\mathrm{Z}$ is the distance between the object and the observer and $\mathrm{e}$ is the height of the object below the horizon, expressed as a visual angle (Warren \& Whang, 1987). These equations show that although the perceived height and distance of an object are not directly linked, both depend on the horizon and thus the effective eye height of the perceiver-actor. Hence, our results can be interpreted as a direct effect of the perceived eye height on the perceived minimum barrier height, even though the perceived distance could also be affected in a concomitant way.

One can also consider the fit between perception and action: in the baseline condition, the perceiver-actor judged the critical height of the barrier (i.e. under which they thought they could pass without ducking), to be lower (at $165.03 \mathrm{~cm}$ ) than their real standing height $(168.24 \mathrm{~cm})\left(\mathrm{BH}_{\operatorname{minp}} / \mathrm{H}=\right.$ 0.98). At first glance, this result contradicts the hypothesis whereby there is a fit between perceived and actual affordance. However, if we consider the perceived eye height and not the real eye height, we find that the former was underestimated by $4.33 \%$ in the baseline condition. This might be due to the fact that perception in our experiments occurred in a very impoverished environment and in the absence of movement. Without this underestimation, the perceived minimum height would have been higher by $7.14 \mathrm{~cm}(165.03 \mathrm{~cm} \times 4.33$ / 100). Thus, without this underestimation, the perceived minimum height would have been 1.023 times their own standing height: $\mathrm{BH}_{\text {minp }} / \mathrm{H}=(165.03+7.14) / 168.24=1.023$. This critical ratio is lower than (but very close to) that determined by Van der Meer (1.038). It appears that individuals have lower safety margins when they merely have to judge whether they can pass under a barrier or not than when they actually have to perform the action. This result is in agreement with that found by Warren \& Whang (1987). Concerning the passability through an aperture (in width), these authors found a $\pi$ ratio of 1.30 when the action was carried out. This ratio was higher than that measured with the perceptual judgments (1.16). Moreover, the perceived ratio of critical height relative to the perceived eye height measured in the present work $\left(\pi_{p}^{\prime}=\mathrm{BH}_{\min } / \mathrm{EH}_{\mathrm{p}} ; \pi_{\mathrm{p}}^{\prime}=1.10\right)$ is not significantly different from the real eye-height ratio $\left(\pi^{\prime}=\mathrm{BH}_{\min } / \mathrm{EH}=1.038 / \mathrm{c} ; \pi^{\prime}=1.11\right.$ with $\left.\mathrm{c}=0.93\right)$ computed from Van der Meer's results. This agreement between the effective and perceived ratios supports the usefulness of an eye-height ratio for specifying the ability to walk under a barrier. The fact that underestimation of the perceived eye height affected the perception of affordance in the present experiment does not undermine the eyeheight ratio's utility. The experimental room was a relatively impoverished environment, chosen in 
order to avoid bias in the judgments (see the "Material and apparatus" section). In a well-lit, natural environment, the eye-height underestimation would be lower (Stoper \& Cohen, 1986). Furthermore, at a distance close enough to actually pass under a barrier (e.g. through a door), the effective eyeheight estimate usually becomes more accurate and thus the perception of affordances does as well (Mark, 1987). Thus, it is reasonable to suppose that if our participants had been able to walk towards the barrier (as in Van der Meer's study) and/or if they had been placed in a more natural visual environment, they could have made more accurate judgments.

In summary, the perception of the ability to walk under a barrier without ducking one's head may be based on picking up a specific eye-height ratio $\left(\pi_{p}^{\prime}=1.10\right)$. If the barrier is less than 1.1 times their effective eye height, individuals perceive that they can not pass under it without ducking. In contrast, if the barrier height is over 1.1 times their effective eye height, they perceive that they can pass under it without changing their posture while walking. Picking up this information in the ambient global array (via different perceptual systems) allows individuals to adapt their behavior in real time and pass under the barrier safely. Thus, the individual can guide his own behavior by picking up intrinsic information, a multimodal invariant extracted from visual, vestibular and somesthetic cues. This multimodal invariant specifies what the environment offers him (her) in terms of possible actions relative to his (her) own capabilities. The use of this information is based on a plastic mechanism which allows a high degree of adaptability.

\section{BIBLIOGRAPHY}

Gibson, J. J. (1979). The ecological approach to visual perception. Hillsdale, New Jersey: Lawrence Erlbaum Associates.

Howard, I. P. (1982). Human visual orientation. New-York: John Willey and Sons.

Luyat, M., \& Regia-Corte, T. (in press). Les affordances de James Jerome Gibson aux formalisations récentes du concept. L'Année Psychologique.

Mark, L. S. (1987). Eyeheight-scaled information about affordances: a study of sitting and stair climbing. Journal of Experimental Psychology: Human Perception and Performance, 13, 361-370.

Ooi, T. L., Wu, B., \& He, Z. J. (2001). Distance determined by the angular declination below the horizon. Nature, 414, 197-200.

Oudejans, R. R. D., Michaels, C. F. M., Bakker, F. C., \& Dolné, M. A. (1996). The relevance of action in perceiving affordances: perception of catchability of fly balls. Journal of Experimental Psychology: Human Perception and Performance, 22, 879-891.

Regia Corte, T., Luyat, M., Darcheville, J-C., \& Miossec, Y. (2004). La perception d'une affordance pour une posture verticale par les systèmes perceptivo-moteurs visuel et haptique. L'Année Psychologique, 104, 169-201.

Sedgwick, H. A. (1980). The geometry of spatial layout in pictural representation. In M. Hagen (Ed.), The perception of pictures VI (pp. 33-90). New-York: Academic Press.

Stoffregen, T. A. (2003). Affordances as properties of the animal-environment system. Ecological Psychology, 15, 115-134. 
Stoper, A. E., \& Cohen, M. M. (1986). Judgments of eye level in light and darkness. Perception and Psychophysics, 40, 311-316.

Turvey, M. T. (1992). Affordances and prospective control: An outline of the ontology. Ecological Psychology, 4, 173-187.

Van der Meer, A. L. H. (1997). Visual guidance of passing under a barrier. Early Development and Parenting, 6, 149-157.

Warren, W. H. (1984). Perceiving affordances: visual guidance of stair climbing. Journal of Experimental Psychology: Human Perception and Performance, 10, 683-703.

Warren, W. H., \& Whang, S. (1987). Visual guidance of stair climbing. Journal of Experimental Psychology: Human Perception and Performance, 13, 371-383.

Wraga, M. (1999). Using eye height in different postures to scale the heights of objects. Journal of Experimental Psychology: Human Perception and Performance, 25, 518-530.

Wraga, M., \& Proffitt, D. R. (2000). Mapping the zone of eye height utility for seated and standing observers. Perception, 29, 1361-1383. 